\title{
The research of development prospects for advertising design under the background of new media
}

\author{
Lijun ZHANG \\ Sichuan Agricultural University \\ Sichuan, China
}

\begin{abstract}
Network technology is the main development trend of today's society, and network technology as the representative of new media has become the main way of modern information design, which brings infinite convenience for the life of people. Through the analysis of related problems under the background of new media advertising design, this article discusses the background of new media advertising design development prospects.
\end{abstract}

Keywords- new media; Advertising design; strategy

\section{INTRODUCTION}

new media is a of a new form of media with new technical support system, such as digital magazine, digital newspapers, digital broadcasting, mobile phone message, network, desktop Windows, digital TV, digital movie, touch media, etc. Relatively to the four traditional medias, newspapers, radio, television, magazines, new media is vividly called the "fifth media". Compared with the traditional media, it also has its own unique characteristics, namely, interactivity and timeliness, mass and sharing, multimedia and hypertext individual and community. New media quickly gets the audience's favor with their quick design speed, low cost, large amount of information, rich content, low cost of the global design, convenient retrieval

\section{OVERVIEW OF ADVERTISING DESIGN}

Advertising design is means of publicity that openly and widely pass information to the public for some specific needs, through some form of the carrier, and consumption of certain costs,. Advertising has a broad sense and narrow sense, general advertising include non-economic advertising and economic. Non-economic advertisement refers to the advertisement that is not for profit, such as government administrative departments, social institutions and even personal various public announcements, advice, statement, etc. Special advertising refers to only economic advertising, also called commercial advertising, which refers to the profit for the purpose of advertising. It usually is the important means of information commodity producers, operators and consumers to communicate, or important form of marketing products to promote the products, capture market and provide labor services. Advertising design is the design to strengthen sales.
The earliest advertising design is small billboards in the newspaper with the form of design. Advertising design need to use visual elements to design the designer's intentions, with text and graphics to convey the information to the audience, and let people willing and pleasant to accept.

Graphic is the important element forming the character of advertising design and improving the attention. Plane graphic design itself is a symbolic expression which the designers to use to convey to the audience itself and conclusion, reaching the purpose of guiding or persuading; in other words, audience, is through the designer's work, also with their own experience to confirm, eventually understand the designers' feeling and thought wish to express.

There are many ways of advertising design: posters, newspapers, magazines and advertising light box advertising, etc.

Advertising is a way to deliver information, and also a kind of business communication. The Medias between advertisers and the audiences in our daily life at any time are likely to come into contact with the advertisement information. Open newspaper, turn on the TV, and surf on the Internet, and the ads can be seen everywhere. It has penetrated into every aspect of our lives, and city dwellers also are accustomed to it. We can recall that a long time ago, when newspaper appeared, we saw a lot of side of your life, and knew a lot of business through the newspaper reports, news, etc. With the rapid development of society, the colorful, beautiful format posters appeared, from complex to simple designs design enhancing the strength and popularity of advertising. Therefore, advertising was born from the side, but also grows in ordinary life.

\section{THE DEVELOPMENT DIRECTION OF ADVERTISING DESIGN}

\section{A. humanized design}

People are social animals with the social attribute. Human nature is refers to the normal emotional and rational feeling of people in all kinds of social relations. Humanized design is based on the study of physical and mental, making a design more accord with people's needs. This need not only is the material requirement, also including the demand of spirit more. In today's era of intangible, human greatly pursue a high level of demand in the heart when meet the basic physiological needs. Humanized design is people first, create a high level physical world for human where people can make the human nature fully released, and express emotion fully, so as to achieve harmony. Advertising design 
carries on the responsibility of comforting the human spirit and heart. If advertising design what to achieve the ultimate goal of promoting sales, inspiring people's deepest desire and the desire to buy, the designer must deeply study and understand the psychology of the different social groups. With people-oriented theme, all aspects of human life, human feelings and needs formed the basis of advertising design ideas and conditions.

\section{B. green designs}

Traditionally, ethics refers to the ethical relationship between man and society, but ethics in the modern sense refers to the ethical relationship between people and the environment. Green design require the advertising designers should set up the design concept to protect the natural environment, save resources, people-oriented, harmony with nature with the need of times,

The idea reflected in advertising design work, on the one hand, meet the basic needs of people and achieve good function. On the other hand, adapt to changing times of aesthetic standards and prevent visual pollution. Many past advertising design work is in pursuit of a strong visual impact, which makes people trapped in the excitant color, lack of creativity in the graph. Scientific research proves that: when people watch the strong stimulation graphics like stretch hand to touch the hot potato, they can produce a kind of instinct to protect themselves. As a result, the concept of green design is the call of the times, aimed at making advertising design in a reasonable visual development, and achieves harmony with human. In addition, express a concern for nature and the environment through the communication with images of nature and philosophy, which also has very important significance. Advertising Design major has started the professional advertising language as a trend in today's design. In addition, designers have realized that they play an important role to save paper and decrease environmental pollution. People-oriented green design will be the long-term needs of the development of advertisement design.

\section{C. globalization and localization}

Another trend in the development of information age advertising design is a combination of traditional culture and modern advertising. Traditional culture as a kind of design resource has been often discussed in a type of resource. Conceptually, traditional connotation is very rich. It includes the traditional material remains that human directly use, imitate and transform, also the traditional non-material culture of different countries and people, especially the traditional way of thinking. Non-material in the era of information technology is increasingly turning the world into a global village. The development of information technology, on the one hand, directly results in the monopoly of internationalism language development. Meanwhile, it promotes the comprehension and mix of design each different race culture on the earth. East and west, south and north communicate through frequent and close contact of the global village. The internationalization of advertising design eliminates the borders, easily understood and accepted by the crowd of different national, regional and national. Under the trend of internationalization, in fact, there are also opportunities for the development of our national culture and possibilities. Modern advertising design is not completely monopoly facing a single style, but a unified change under the new communication premise.

\section{THE PROBLEM OF ADVERTISING DESIGN DEVELOPMENT}

\section{A. The use of photography works in advertising design}

This form should be the main form of journal of advertising design. The art of photography is used in advertising design, advertising design touches in photography. Respecting and developing one's personality are advocated in the nonphysical times. Designers must pay attention to the excavation design elements from the national culture and local culture; making the design reflects the ethnic characteristics.

\section{B. The development of the breakthrough of three- dimensional computer design in the journal of advertising}

The development of the breakthrough of threedimensional computer design in the journal of advertising

Three-dimensional computer animation design has made great breakthrough in recent years in the design field of rapid development design and penetrate in all kinds of graphic design, journal of design.

Upper ads show a picture by all sorts of colorful images of three-dimensional graphics after desalination. Strange, fascinating, visual effect is very good. Three-dimensional computer design is just coming into the advertisement design and will become one of the main forms of the advertisement design development in the future. It is quite a long time in the future that there will be a bigger development. Advertisement designers must not underestimate this form to make it better used in the design, for advertising sales promotion services.

\section{C. advanced computer plate-making technology also has a wide application in design of advertisement design}

In recent years, computer plate-making has entered into a new level from electronic color separation into the stunt processing with a computer screen.

Now many cities have introduced this new technology in advertising design. Now the advertisement design not only can use a computer to the female, move feeling, Mosaic, such as watercolor, oil painting plane stunt processing arc image, but also can use a computer to column, ball, wind, wave, vortex, extrusion and expansion, perspective, and twisted, mixing and dealing with three-dimensional effects, photo or color. Computer generated further the application of new technology design personnel from design and production process of manual operation, making a design layout more normal standard and vivid. 


\section{All kinds of arts and crafts entering the design field of advertisement design}

Advertising works more colorful: painting, drawing, watercolor, turbulence tracing art forms. There are more widely used. As in advertising design in the "emperor" the castle "of building is it; In the "metamorphosis" colorful partial also is to use watercolor to me now; "Welcome to the 21st century" in the red tail, a pencil, film, is appropriate foot print effect and so on. It shows that the design of the advertisement design has gradually matured, and various forms of art are widely used in advertising design. We should keep the good situation of "flowers flourishing" and make periodical advertising opened a new flower, to meet the needs of the market to promote shop.

Analysis of the elements of 5 advertising design development prospects

\section{FACTORS ANALYSIS OF ADVERTISING PROSPECT}

\section{A. make scientific budget planning}

Advertising is the premise and guarantee for normal operation of the advertising market. With advertising costs well prepared, advertising market can function smoothly. In order to make the advertisement cost efficiency to the largest, advertising planners should do a good job of advertising expenses budget. Advertising planning department can try to establish a scientific and perfect assessment system for advertising, to evaluate the advertising. But under the background of new media advertising the assessment work is much harder. Advertising assessment workers not only evaluate the value of advertising, but also evaluate the characteristics and the ratio of advertising. Then determine the cost of investment in the advertising design. For example, SUVs vendors want to advertise on the electronic magazine, because professional magazines can improve car's profile. But the seller should first consider the advertisement cost performance and the actual value. Only performance-to-price ratio is high, the value of the advertising is worth the advertisement. According to the information, a scientific planning should be made. The unnecessary advertising costs can be reduced and improve the efficiency of the use of advertising.

\section{B. advertising design combining a variety of new media}

New media has many forms, and advertising design cannot be confined to a kind, which can't increase attention of the advertisement. The advertising design should be combined with a variety of media. The first is the combination of a variety of new media, because the different kinds of new media, design methods and effects are also different. Advertising planners should use the advantages to design advertising. Advertising planners can design a short advertisement, about $1 \mathrm{~min}$, and put the advertisement video on web site. When people use cell phones, according to watching TV or video shows, they can play the first small ads. It raises the awareness of the advertising.

The second is the combination of new media and traditional media. Although new media develop rapidly in the modern and praised by many young people, the traditional media, also don't lose its charm. Therefore, advertising design should also take traditional media into account the use a combination of both to design.

\section{Advertising design to innovate in the design form}

Under the background of new media, advertising design should make good use of the advantage of new media to figure out the preferences of the masses in a lot of advertising information, so as to attract the attention of the masses. Under the background of new media, the advertisement which is creative, novel form and dynamic, appealing and can bring the visual impact will cause the attention of the masses.

\section{Perfect the relevant laws and regulations of the advertising}

Due to the variety of new media, large amount of information of design, more complex design way, someone will use to design some illegal information, pollute audience eyeballs, and others will make illegal information into invisible seemingly normal web link or website, and mislead people to click on to gain attention, so relevant departments should compiled the rules of some new media advertising in the design to these information, and formulate measures for the handling of illegal advertisement information especially some illegal, pornographic advertising information processing method and so on, so as to make the specification for better behavior of advertising designers.

\section{CONCLUSIONS}

Under the background of new media, China's current advertising design appeared stereotyped phenomenon and does not reflect the creative wisdom.

Designers considering the problems should be based on the consumer as the center, on the basis of the objective life world in advertising design to make a design, letting consumers return true not illusory dreams.

\section{References}

[1] Wang Nan. Introduction to new media under the background of how to do a good job in publicity work $[\mathrm{J}]$. Journal of news design, and practices of 2014:283-284.

[2] Zhang Ruohui. Development trend of the theory of the information age advertising design $[\mathrm{J}]$. Modern commercial and trade industry, and practices of 2012:78-79.

[3] Liu ping. Discuss about the development of advertisement design [J] Science and technology innovation and application, 2012, 19:42.

[4] Yao Shuangxi. Under the background of the new media of radio and television language study [J]. Journal of language application, 2012 01:41-45.

[5] Zhao Lili. The development trend of China's advertising design, theory of how to properly treat the traditional culture [J]. Journal of education teaching BBS, 2011, 21:231-232.

[6] Tian Jianyun. The development of China's advertising design [J]. Journal of China press, 1995, 12:52-54.

[7] Yuan Qiuyue. Read the development trend of advertising design [J] Journal of art, 2007, 12:100. 